Research Article

\title{
Near-Field HF-RFID and CMA-Based Circularly Polarized Far-Field UHF-RFID Integrated Tag Antenna
}

\author{
Arnon Sakonkanapong $\mathbb{D}$ and Chuwong Phongcharoenpanich \\ Faculty of Engineering, King Mongkut's Institute of Technology Ladkrabang, Bangkok 10520, Thailand \\ Correspondence should be addressed to Chuwong Phongcharoenpanich; chuwong.ph@kmitl.ac.th
}

Received 11 January 2020; Revised 17 March 2020; Accepted 21 March 2020; Published 24 April 2020

Academic Editor: María Elena de Cos Gómez

Copyright (C) 2020 Arnon Sakonkanapong and Chuwong Phongcharoenpanich. This is an open access article distributed under the Creative Commons Attribution License, which permits unrestricted use, distribution, and reproduction in any medium, provided the original work is properly cited.

\begin{abstract}
This research proposes an integrated high-frequency (HF) and ultrahigh-frequency (UHF) passive radio frequency identification (RFID) tag antenna for near-field $(13.56 \mathrm{MHz})$ and far-field $(920-925 \mathrm{MHz})$ communication. This tag antenna is advantageous for the applications with lossy material in the near-field communication and mitigates polarization loss in the far-field communications. The HF-RFID tag antenna is of square spiral structure, and the circularly polarized UHF-RFID structure consists of a square loop radiator with cascading loop feeding and shorted stub. The structure of HF-RFID tag antenna situated inside the circularly polarized UHF-RFID tag can avoid the significant effect of the near-field magnetic coupling from the square loop. The UHF-RFID tag antenna is realized by using characteristic mode analysis for wideband circular polarization. The HF-RFID structure is conjugate-matched with NXP NT3H2111 chip, and the UHF-RFID structure is conjugate-matched with NXP G2X chip. Simulations were carried out, and an antenna prototype was fabricated. The experimental results reveal that the radiation pattern of UHF-RFID tag antenna is bidirectional with a gain of $0.31 \mathrm{dBic}$. The impedance bandwidth covers the frequency range of $903-944 \mathrm{MHz}$, and the axial ratio in boresight direction at $922.5 \mathrm{MHz}$ is $1.67 \mathrm{~dB}$, with the axial ratio bandwidth over $863-938 \mathrm{MHz}$. The maximum near-field and far-field reading ranges are $4.9 \mathrm{~cm}$ and $8.7 \mathrm{~m}$. The proposed integrated dual-band passive tag antenna is operationally ideal for HF-RFID and UHF-RFID applications.
\end{abstract}

\section{Introduction}

Radio frequency identification (RFID) technology has been employed in various applications, including object or person identification and tracking and toll collection [1]. There are two classifications of RFID: near-field and far-field communication. The operating frequency of RFID near-field communication is high frequency (HF) of $13.56 \mathrm{MHz}$, and those of RFID far-field communication are ultrahigh frequency (UHF), $2.4 \mathrm{GHz}$ and $5.8 \mathrm{GHz}$ bands. Allocation of UHF-RFID frequency $(860 \mathrm{MHz}-960 \mathrm{MHz})$ varies from country to country. In this research, the UHF-RFID operating frequency is $920 \mathrm{MHz}-925 \mathrm{MHz}$ (center frequency of $922.5 \mathrm{MHz}$ ), which is the frequency allocation in China (upper band), Hong Kong, Singapore, Thailand, and Vietnam [2].

In RFID tag antenna, the communication distance and frequency band are subject to application, reader capability, and implementation cost. For specific applications, RFID tag antennas with near-field and far-field communication capability are required, such as in highway tracking and toll collection. The RFID near-field communication in HF band has the benefit that the prominent magnetic field can penetrate the lossy materials and other dielectric media such as glass or other components of vehicles. The larger memory in HF-RFID tag is capable of storing the important information such as car owner name, registration information, and others. This is very convenient for officers to inspect some information for special circumstance. For RFID farfield communication using electromagnetic radiation in the UHF band, the tag antenna can be operated in long distance that can provide the positioning and tracking for various vehicle types. This fact necessitates integration of near-field and far-field RFID antennas in HF band and UHF band into one single structure. 
In the literature, the research on antenna design for RFID near-field and far-field communication has been presented for either single band or dual-band operation. The target of greater performance with compact dimension is desirable. The RFID near-field and far-field antennas operating in dual HF band and UHF band have been presented in [3-7]. To conserve the antenna size, the HF-RFID and UHF-RFID tag antennas were designed in proximity with good isolation [3-5]. Alternatively, the design of the dualband RFID tag antennas is to accommodate the UHF-RFID tag antenna into the HF-RFID tag antenna because the typical HF-RFID tag antenna is relatively larger due to lower frequency operation [6, 7]. Specifically, the near-field RFID capability is realized by using planar coil structures, and the far-field UHF-RFID capability is achieved using Hilbert curve [3], C-shaped radiator [4], bent rectangular patch [5], meander line [6], and S-dipole [7]. These antennas [4-7] can be communicated with the RFID reader antenna using magnetic coupling in HF band and electromagnetic radiation in UHF band. The far-field tag antennas of linearly polarized radiation are prone to polarization mismatch with reader antenna. As a result, far-field tag antennas with circularly polarized $(\mathrm{CP})$ radiation are more operationally desirable. In [3], the idea of designing the integrated nearfield tag antenna with circularly polarized far-field tag antenna using Hilbert curve structure is proposed. However, the main beam is shifted from the boresight direction, and the difference between impedance of the antenna and that of the chip is pronounced. This is impractical for the implementation.

To realize CP radiation, most tag antennas [8-20] have been designed only for far-field radiation in UHF band. The $\mathrm{CP}$ tag antennas for UHF-RFID band with modified slit $[8-10]$ and slot $[11,12]$ are proposed. The inverted-Z geometry [13] and meandered loop [14] are utilized to generate $\mathrm{CP}$ radiation. In [15-17], both meandered and orthogonal techniques are used to realize CP radiation. The simple loop structure is implemented to generate CP radiation [18-20]. However, these circularly polarized tag antennas [8-20] suffer from relatively narrow axial ratio bandwidth (ARBW). To realize CP radiation with enhanced ARBW, characteristic mode analysis (CMA) is utilized in the UHF-RFID tag antenna design. CMA characterizes the modes of current on perfect electric conductor (PEC) of arbitrary conductor object to obtain characteristic modes that generate circular polarization. CMA [21-23] has been applied to optimize the antenna excitation locations $[24,25]$ to design tilted-up radiation pattern [26] and to enhance impedance bandwidth [27, 28].

The crucial challenge of this research is to design the integrated dual-band passive HF-RFID and UHF-RFID tag antenna for near-field and far-field communication with great performance, compact structure, and cost effectiveness. The integrated structure is made up of the HF-RFID tag antenna situated inside the circularly polarized UHF-RFID tag. This model is introduced to avoid the significant effect of the near-field magnetic coupling from the portion of UHFRFID tag antenna to the HF-RFID tag antenna. The nearfield HF-RFID communication can be efficiently performed with lossy materials and other dielectric media. Furthermore, the design goal of the far-field UHF-RFID tag antenna is to achieve circularly polarized radiation for mitigation of polarization loss in some scenarios such as misalignment with reader antenna and multipath propagation environment. With limitation of structural compactness, the design of circularly polarized UHF-RFID tag antenna with enhanced axial ratio bandwidth (ARBW) is advantageous.

The compact HF-RFID tag antenna of square spiral structure is initially designed based on modified Wheeler formula to conjugately match with NT3H2111 chip at 13.56 MHz. Then, the UHF-RFID square loop tag antenna, relying on the CMA principle using characteristic angle difference, is realized to surround HF-RFID tag antenna with achievable wideband $\mathrm{CP}$ radiation. The inductive coupling element (ICE) technique has been applied for designing the proper CP excitation location. The UHF-RFID tag antenna with a square loop radiator with cascading square loop feeding structure is conjugate-matched with NXP G2X chip at 922.5 MHz. Simulations were carried out, and an antenna prototype was fabricated. The proposed integrated HF-RFID and UHF-RFID tag antenna is operable over $13.56 \mathrm{MHz}$ and $920-925 \mathrm{MHz}$ frequency range.

\section{Antenna Configuration and Design}

To design the integrated dual-band HF-RFID and UHFRFID tag antenna for near-field and far-field communication, the antenna characteristics must meet the system requirements. The antenna size and its performance must be traded off. Usually, the antenna size should be less than or equal to a quarter wavelength of its lowest operating frequency. The antenna configurations should be conjugatematched with integrated circuit (IC) chips of each band. The HF-RFID tag antenna is miniaturized to locate inside UHFRFID tag antenna. The far-field UHF-RFID tag antenna encompasses the HF-RFID tag antenna and radiates circularly polarized directional pattern. The antenna gain is closed to that of the dipole antenna with equivalent electrical length (1-2 dBic). The axial ratio (AR) must be less than $3 \mathrm{~dB}$ over the entire bandwidth that is widened to cover regulated frequency bands in various countries.

The IC chips of NXP NT3H2111 and NXP G2X are used in the design of the HF-RFID and UHF-RFID passive tag antenna. The dual-band tag antenna is conjugate-matched with the IC chips to maximize power transfer between the IC chips and the antenna. Table 1 tabulates the characteristics of the RFID chips.

In conjugate matching, the impedance of IC chip is first determined. In Table 1, the input capacitance $(C)$ of NXP $\mathrm{NT} 3 \mathrm{H} 2111$ chip at $13.56 \mathrm{MHz}$ is $50 \mathrm{pF}$, and the corresponding capacitive reactance is $234.73 \Omega$. Ideally, the proposed HF-RFID tag antenna should possess an inductive reactance of $234.73 \Omega$. Meanwhile, $C$ and quality factor $(Q)$ of NXP G2X chip for UHF-RFID band (920-925 MHz) are $1.16 \mathrm{pF}$ and 9.37. The capacitive reactance and resistance at $922.5 \mathrm{MHz}$ (center frequency) are $148.73 \Omega$ and $15.87 \Omega$. Ideally, the UHF-RFID tag antenna should possess an 
TABLE 1: Characteristics of RFID IC chips.

\begin{tabular}{lcc}
\hline Model (band) & $\begin{array}{c}\text { NXP NT3H2111 (HF- } \\
\text { RFID) }\end{array}$ & $\begin{array}{c}\text { NXP G2X (UHF- } \\
\text { RFID) }\end{array}$ \\
\hline Input capacitance & $50 \mathrm{pF}$ & $1.16 \mathrm{pF}$ \\
$(C)$ & $\mathrm{N} / \mathrm{A}$ & 9.37 \\
Quality factor $(Q)$ & & \\
\hline
\end{tabular}

impedance of $15.87+\mathrm{j} 148.73 \Omega$ so as to conjugate match with the NXP G2X chip whose impedance is $15.87-\mathrm{j} 148.73 \Omega$.

2.1. HF-RFID Tag Antenna. Given the input capacitance of NT3H2111 chip at $13.56 \mathrm{MHz}$ of $50 \mathrm{pF}$, the inductance of the HF-RFID tag antenna should be $2,755 \mathrm{nH}$, corresponding to its inductive reactance of $234.73 \Omega$. To realize the inductance, a square spiral inductor is used in the HFRFID tag antenna due to high immunity to a wide range of process variations.

Figure 1 illustrates the configuration of square spiral HFRFID tag antenna with $5 \mathrm{~mm}$ access line. The square spiral inductor is printed on FR4 substrate whose dielectric constant and thickness are 4.3 and $0.8 \mathrm{~mm}$. The inner and outer dimensions of the square spiral structure are represented by $d_{\text {in }}$ and $d_{\text {out }}$. The turn width $(W)$ and the turn spacing are identical.

The initial dimension of the square spiral structure is approximated by modified Wheeler formula (MWF) $[29,30]$. In theory, the inductance of the square spiral structure (Figure 1) is a function of permeability, turn width, turn spacing, and the number of turns. The inductance $(L)$ of the square spiral structure can be expressed as

$$
\begin{aligned}
& L=2.34 \mu_{0}\left[\frac{n^{2}\left(d_{\text {out }}+d_{\text {in }}\right)}{2(1+2.75 \rho)}\right], \\
& \rho=\frac{\left(d_{\text {out }}-d_{\text {in }}\right)}{\left(d_{\text {out }}+d_{\text {in }}\right)}
\end{aligned}
$$

where $\mu_{0}$ is free-space permeability, $n$ is the number of turns, $d_{\text {out }}$ is the outer dimension, $d_{\text {in }}$ is the inner dimension, and $\rho$ is the fill ratio.

Due to fabrication constraints, the turn width $(W)$ and turn spacing remain constant at $1 \mathrm{~mm}$. The initial $d_{\text {out }}$ of the square spiral structure is $50 \mathrm{~mm}$, which is the width of typical key card. Figure 2 illustrates the inductive reactance of the square spiral structure under variable numbers of turns $(n)$ and $d_{\text {out }}$ i.e., $(4,80),(5,64),(6,55),(7,50),(8,48),(9,47)$, $(10,46)$, and $(11,46)$, with the resulting inductive reactance of $228.96 \Omega-238.17 \Omega$. Ideally, the inductive reactance of the square spiral structure should be $234.73 \Omega(L=2,755 \mathrm{nH})$. As a result, the square spiral structure contains nine turns $(n=9)$ and is $47 \mathrm{~mm}$ in outer dimension $\left(d_{\text {out }}=47 \mathrm{~mm}\right)$, which is subsequently mounted at the center of the UHFRFID square loop tag antenna.

In the near-field communication of HF-RFID system, the magnetic field coupling plays a vital role in the connection between the reader and tag. To assess the

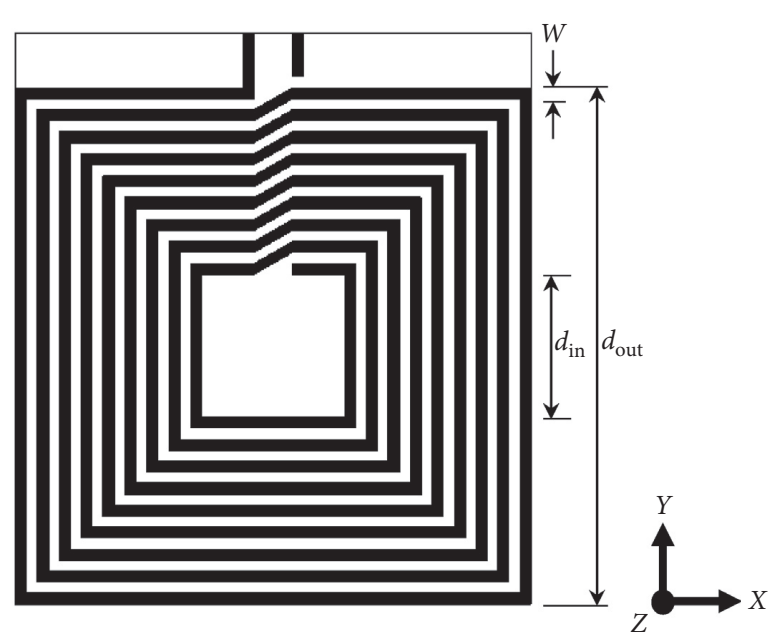

FIGURE 1: The configuration of square spiral HF-RFID tag antenna.

communication performance, the magnetic field intensity of the HF-RFID tag antenna is simulated by CST Studio Suite full-wave simulation software [31]. The reading range of the HF-RFID communication system primarily depends on the magnetic field [32]. However, the estimation of reading range cannot be exactly determined because the certain sensitivity of the HF-RFID tag is not available. Nevertheless, the simulated total magnetic field distributions of the HF-RFID tag antenna for various distances, from the tag surface to $6 \mathrm{~cm}$, are depicted in Figure 3. In principle, the intensity of total magnetic field distribution roughly decays with distance $(d)$ to the power of three $\left(H \sim 1 / d^{3}\right)$ [33]. It is obvious that the magnetic field distribution in Figures 3(a)-3(d) are strong at the surface and near the tag of around $4 \mathrm{~cm}$. When the distance is $5 \mathrm{~cm}$, the intensity of magnetic field is relatively weak as illustrated in Figure 3(e). From the distance of $6 \mathrm{~cm}$ and further, the magnetic field strength is very low as shown in Figure 3(f). The measured reading range associated with this simulated magnetic field distribution will be mentioned in Section 3.

2.2. UHF-RFID Tag Antenna. In the design of the circularly polarized UHF-RFID tag antenna, a square loop radiator is introduced to surround the HF-RFID square spiral structure. In the design of the UHF-RFID square loop tag antenna, characteristic mode analysis (CMA) is utilized to realize circularly polarized radiation. CMA characterizes the modes of current on perfect electric conductor (PEC) of arbitrary conductor object and its radiation property. The modal solution of CMA (equation (2)) is used to investigate the dynamic behavior (i.e., surface current) of the square loop structure to obtain characteristic modes that generate circular polarization. The current on conductor surface $(J)$ is the summation of mode currents and can be expressed as

$$
J=\sum_{n} \alpha_{n} J_{n}
$$




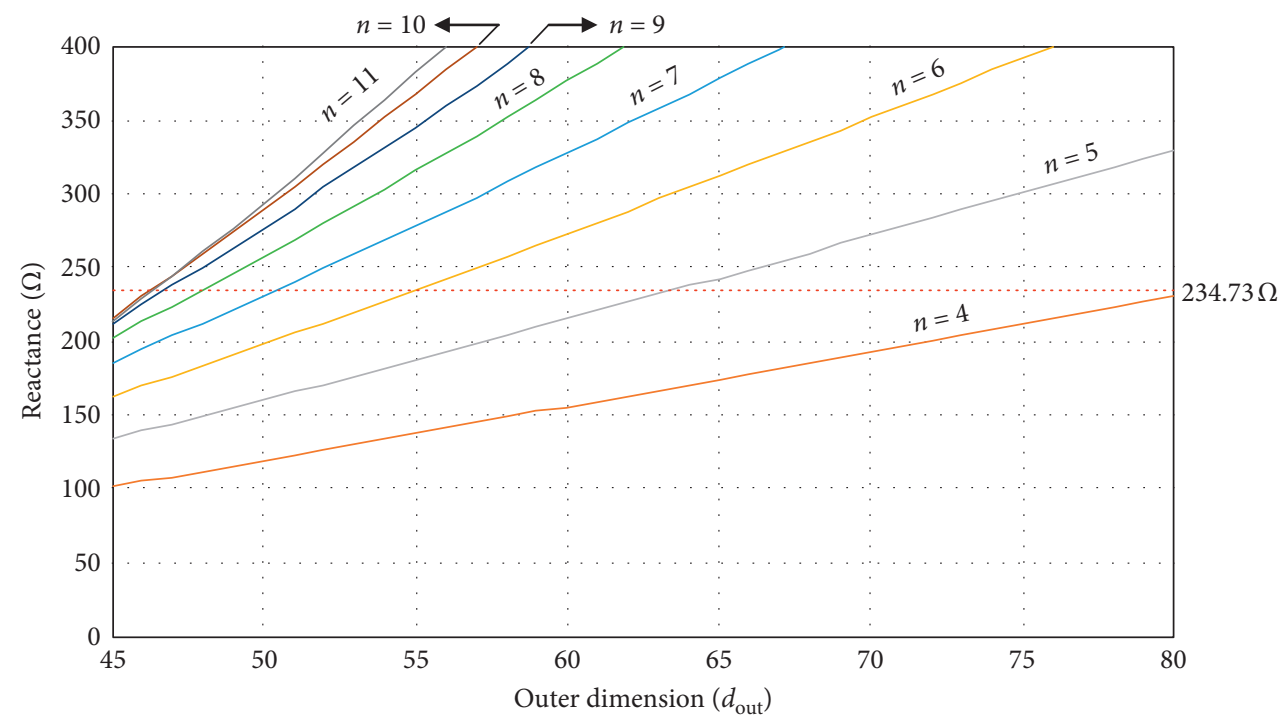

Figure 2: The inductive reactance of square spiral structure under variable numbers of turns $(n)$ and outer dimension $\left(d_{\text {out }}\right)$.

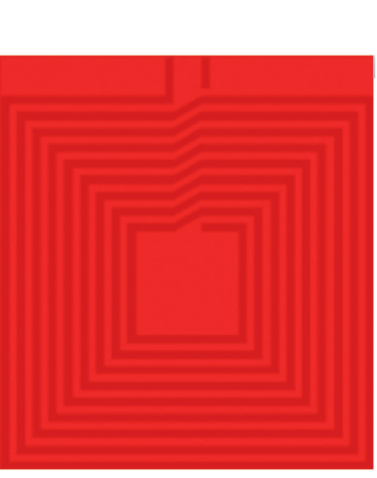

(a)

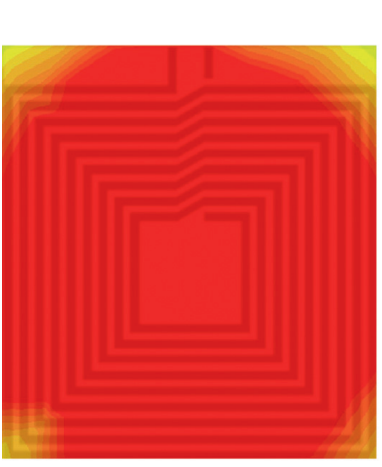

(d)
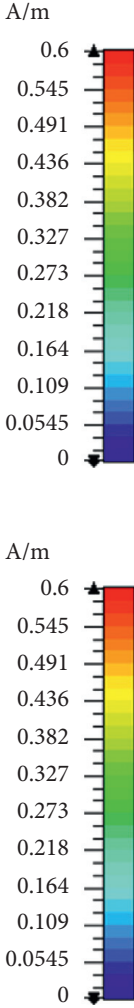

0

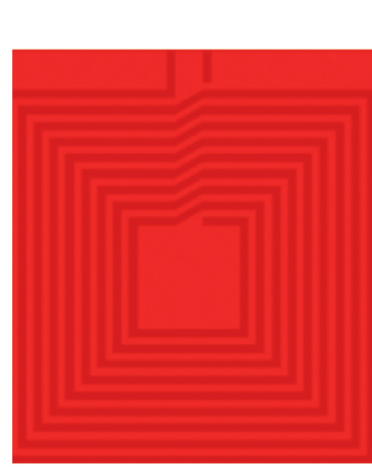

(b)

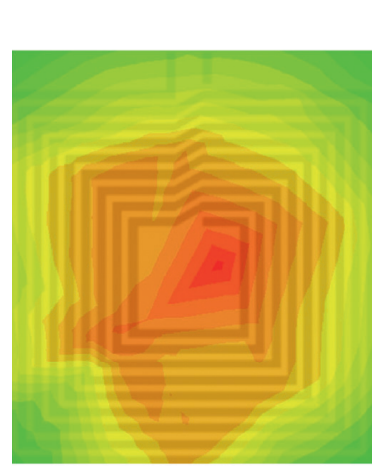

(e)
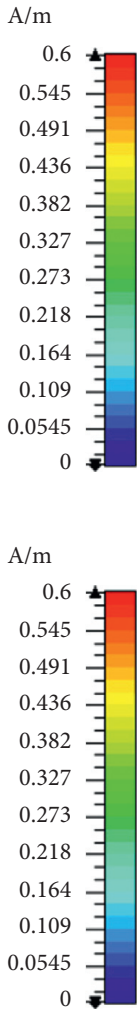

0

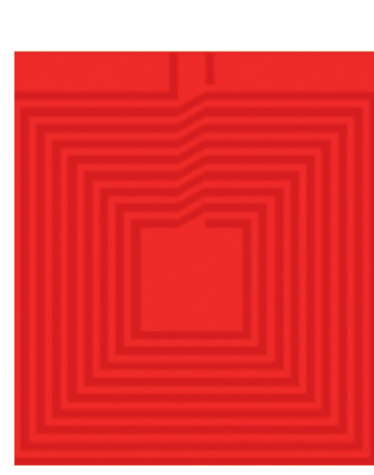

$\mathrm{A} / \mathrm{m}$

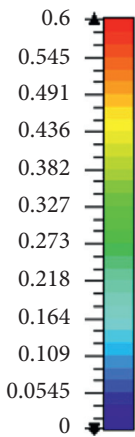

(c)

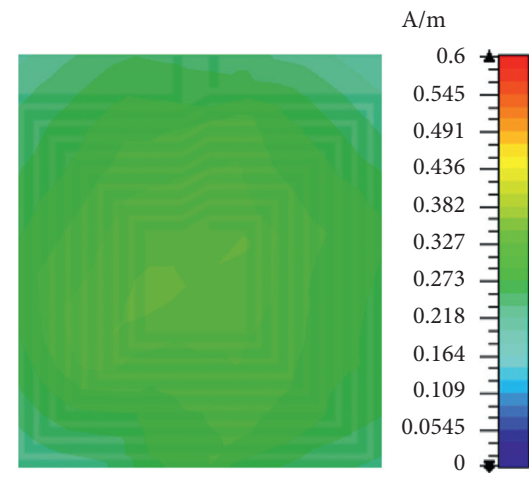

(f)

Figure 3: The simulated total magnetic fields of HF-RFID square spiral structure when varying distance. (a) $0 \mathrm{~cm}$, (b) $2 \mathrm{~cm}$, (c) $3 \mathrm{~cm}$, (d) $4 \mathrm{~cm}$, (e) $5 \mathrm{~cm}$, and (f) $6 \mathrm{~cm}$.

where $\alpha_{n}$ is the modal weighting coefficient and $J_{n}$ is the eigencurrent. The modal weighting coefficient can be expressed as

$$
\alpha_{n}=\frac{v_{n}^{i}}{1+j \lambda_{n}}
$$

where $\lambda_{n}$ is the eigenvalue and $v_{n}^{i}$ is the modal excitation coefficient which is defined by

$$
v_{n}^{i}=\left\langle J_{n}, E^{i}\right\rangle=\oiint_{s} J_{n} \cdot E^{i} \mathrm{~d} S,
$$

where $E^{i}$ is incident electric field and $S$ is the surface of a conductor. 
In CMA, the characteristic modes are determined by the eigenvalue $\left(\lambda_{n}\right)$ or characteristic angle (CA), which is represented by $\beta$ and expressed in equation (5). $\lambda_{n}$ is zero and $\beta$ is $180^{\circ}$ if $J_{n}$ is resonant.

$$
\beta=180^{\circ}-\tan ^{-1}\left(\lambda_{n}\right) .
$$

In realizing the circularly polarized UHF-RFID tag antenna based on CMA, the square loop radiator is initially simulated without excitation. The initial width $\left(W_{1}\right)$ and length $\left(L_{1}\right)$ of the square loop radiator are $3 \mathrm{~mm}$ and $81 \mathrm{~mm}$ (quarter wavelength at the center frequency of $922.5 \mathrm{MHz}$ ), as shown in Figure 4.

In circular polarization $(\mathrm{CP})$ theory, the phase difference of two orthogonal electric field components is $90^{\circ}$ with identical magnitude. Figure 5 illustrates the simulated farfield patterns of the first six modes $\left(J_{1}-J_{6}\right)$ at $922.5 \mathrm{MHz}$ of the CMA-based square loop radiator. In Figures 5(a) and 5 (b), the far-field patterns of modes $J_{1}$ and $J_{2}$ are of nearomnidirectional radiation and orthogonal to each other, rendering them ideal for excitation of $\mathrm{CP}$ radiation.

To generate CP radiation, modes $J_{1}$ and $J_{2}$ are simultaneously excited at optimal excitation locations whose characteristic currents are high. The optimal excitation locations can be determined by inductive coupling elements (ICEs) or capacitive coupling elements (CCEs) [26, 34]. In this research, ICE is used to optimize the excitation locations.

Figures 6(a) and 6(b), respectively, illustrate the simulated characteristic currents of modes $J_{1}$ and $J_{2}$. The current is highly concentrated around regions $A_{1}$ and $A_{2}$ for mode $J_{1}$ and regions $B_{1}$ and $B_{2}$ for mode $J_{2}$. As a result, either region $A_{1}$ or $A_{2}$ for mode $J_{1}$ and either region $B_{1}$ or $B_{2}$ for mode $J_{2}$ of the square loop radiator are excited. $A_{2}$ and $B_{2}$ are selected for the optimal excitation locations, giving rise to a cascading square loop feeding structure as illustrated in Figure 6(c).

Figure 7 shows the eigenvalues of modes $J_{1}$ and $J_{2}\left(\lambda_{1}\right.$ and $\lambda_{2}$ ) and the characteristic angle difference of the square loop radiator with cascading square loop feeding structure over $860-960 \mathrm{MHz}$. At $922.5 \mathrm{MHz}, \lambda_{1}$ and $\lambda_{2}$ are 0.64 and -1.71 , which are close to zero, indicating near-resonant condition. Theoretically, CP radiation is induced when the phase difference between two orthogonal electric fields is $90^{\circ}$. In Figure 7, the characteristic angle difference between modes $J_{1}$ and $J_{2}$ at $922.5 \mathrm{MHz}$ is $92.51^{\circ}$, which is approximately quadrature phase difference for $\mathrm{CP}$ radiation.

To realize the UHF-RFID tag antenna, the square loop radiator with cascading square loop feeding structure is conjugate-matched with NXP G2X chip. A shorted stub is thus introduced into the cascading square loop feeding structure for conjugate matching, as shown in Figure 8.

Given the length of the square loop radiator $\left(L_{1}\right)$ of $81 \mathrm{~mm}$, the initial length of cascading square loop feeding $\left(L_{2}\right)$ is $20 \mathrm{~mm}$. The initial width $\left(W_{\mathrm{c}}\right)$ and total length of the shorted stub $\left(L_{\mathrm{c}}+2 H_{\mathrm{c}}\right)$ are $3 \mathrm{~mm}$ and $39 \mathrm{~mm}$. The square loop radiator with cascading loop feeding is printed on FR4 substrate whose dielectric constant and thickness are 4.3 and $0.8 \mathrm{~mm}$. The initial dimension of the substrate is $101 \mathrm{~mm} \times 101 \mathrm{~mm}$. The optimization of UHF-RFID tag

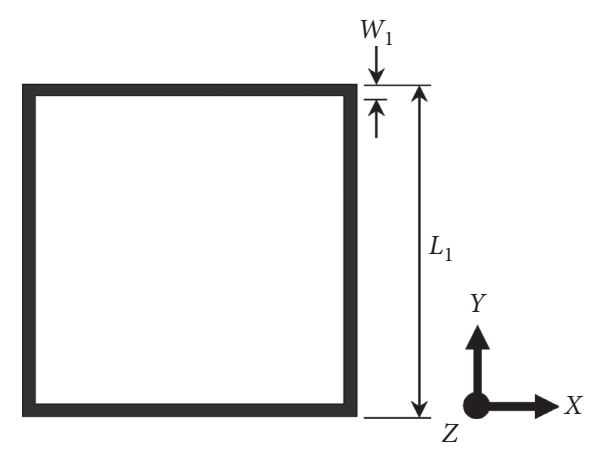

FIgure 4: The initial CMA-based square loop radiator.

antenna parameters is carried out using CST Studio Suite, given the conjugate matching between the UHF-RFID tag antenna and the NXP G2X chip and $\mathrm{AR}<3 \mathrm{~dB}$. Table 2 tabulates the initial and optimal UHF-RFID tag antenna parameters.

Figures 9(a)-9(c), respectively, illustrate the simulated impedance of UHF-RFID tag antenna at $922.5 \mathrm{MHz}$ under variable shorted stub width $\left(W_{\mathrm{c}}\right)$, length $\left(L_{\mathrm{c}}\right)$, and height $\left(H_{\mathrm{c}}\right)$, given $W_{1}, L_{1}, L_{2}$, and $L_{\mathrm{d}}$ of $3 \mathrm{~mm}, 77.3 \mathrm{~mm}, 17.84 \mathrm{~mm}$, and $24.86 \mathrm{~mm}$. In the impedance simulation, $W_{1}, L_{1}, L_{2}$, and $L_{\mathrm{d}}$ remain constant due to their negligible effect on the conjugate matching, where $W_{1}$ and $L_{1}$ are the width and length of the square loop radiator, $L_{2}$ is the length of cascading square loop feeding, and $L_{\mathrm{d}}$ is the distance between the shorted stub and excitation location. Given the optimal parameters (Table 2), the impedance of the UHF-RFID tag antenna is $14.39+\mathrm{j} 147.94 \Omega$, close to the ideal impedance of $15.87+\mathrm{j} 148.73 \Omega$.

Figures 10(a) and 10(b), respectively, depict the simulated impedance and AR under variable $L_{\mathrm{d}}$, given $W_{\mathrm{c}}, L_{\mathrm{c}}, H_{\mathrm{c}}$, $W_{1}, L_{1}$, and $L_{1}$ of $2 \mathrm{~mm}, 16.38 \mathrm{~mm}, 10.26 \mathrm{~mm}, 3 \mathrm{~mm}$, $77.3 \mathrm{~mm}$, and $17.84 \mathrm{~mm}$. These parameters remain constant as they exert minimal influence on the AR. As previously stated, variation in $L_{\mathrm{d}}$ has minimal effect on the impedance characteristic, while AR and $L_{\mathrm{d}}$ are positively correlated. Given the optimal parameters, the axial ratio of the UHFRFID tag antenna in boresight direction is $1.16 \mathrm{~dB}$.

Figure 11 shows the simulated far-field electric fields under variable time periods $(T)$ in boresight direction at 922.5 MHz. The electric field is rotated counterclockwise with respect to $T$, resulting in left-hand circular polarization (LHCP).

\section{Antenna Prototype and Results}

In the prototype fabrication, the HF-RFID and UHF-RFID structures are integrated on one single FR4 substrate for an integrated HF-RFID and UHF-RFID tag antenna as shown in Figure 12(a). The proposed HF-RFID structure is located inside the square loop radiator of the UHF-RFID structure. This arrangement yields the magnetic field distribution along the square spiral antenna in HF-RFID band. The magnetic field intensity has very weak coupling on the portion of square loop radiator with cascading square loop feeding structure as illustrated in Figure 12(b). Figure 12(c) 


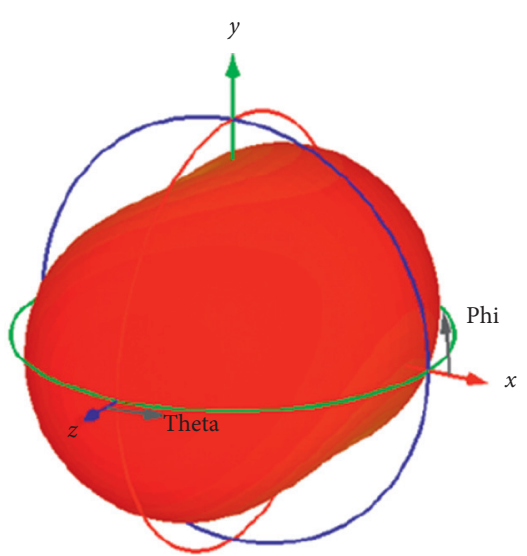

(a)

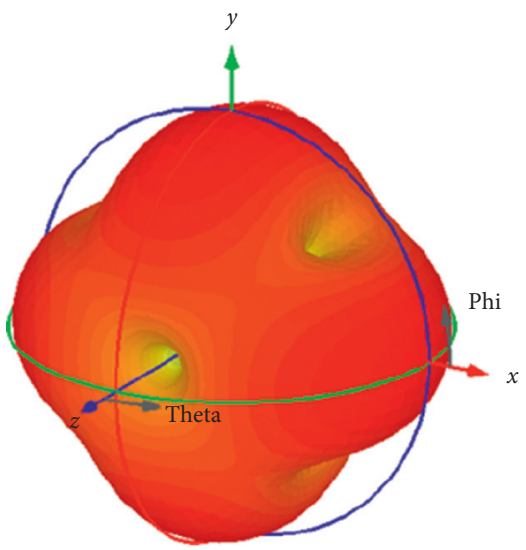

(d)

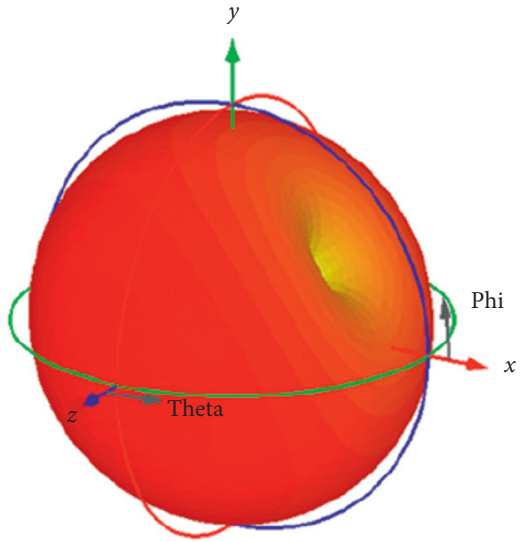

(b)

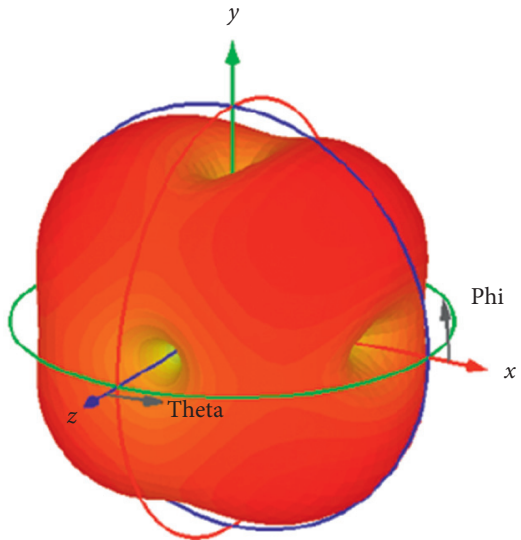

(e)

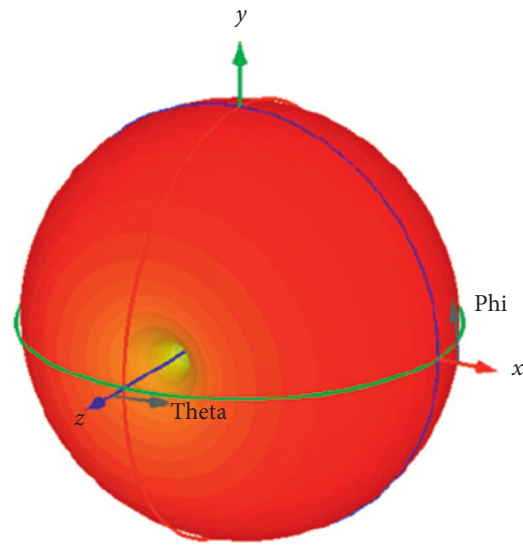

(c)

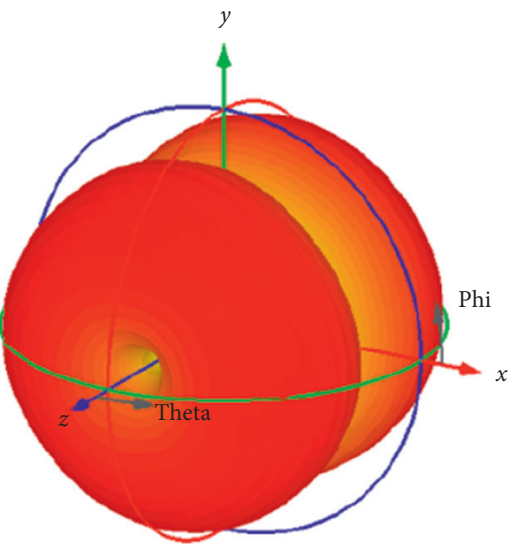

(f)

Figure 5: The simulated far-field patterns of $J_{1} J_{6}$ at $922.5 \mathrm{MHz}$ of the CMA-based square loop radiator.

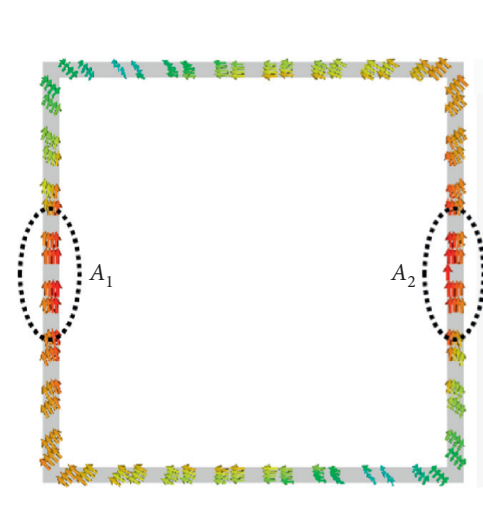

(a)
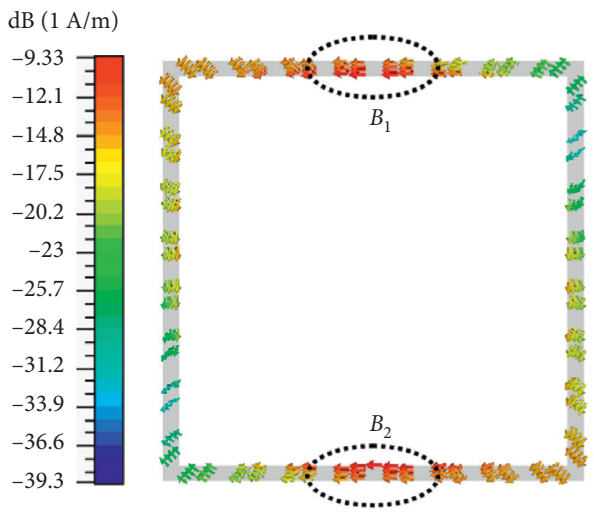

(b)

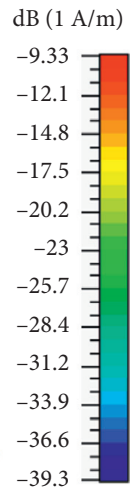

(c)

FIgURE 6: The simulated characteristic currents: (a) mode $J_{1}$, (b) mode $J_{2}$, and (c) cascading square loop feeding structure.

depicts the fabricated prototype antenna that is used for the measurement.

Since the impedance of the HF-RFID and UHF-RFID structures (in the absence of IC chips) are j234.73 $\Omega$ and $14.39+\mathrm{j} 147.94 \Omega$, it is impractical to determine the impedance using $50 \Omega$ network analyzer. As a result, a differential probe is deployed [35], as illustrated in Figure 13.

The network analyzer is calibrated in full two-port network mode. The scattering parameters $\left(S_{i j}\right)$ are used to 


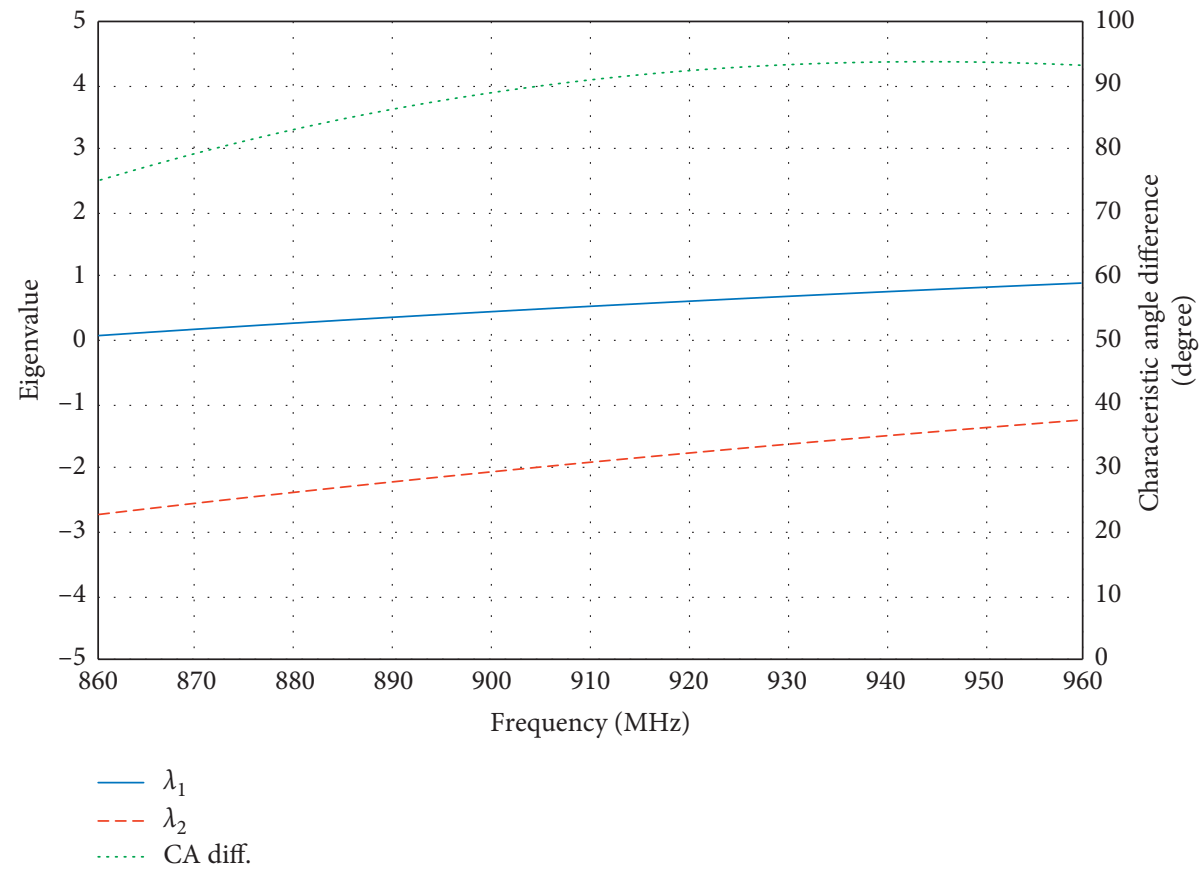

FIgURE 7: The eigenvalues of modes $J_{1}$ and $J_{2}$ and characteristic angle difference between modes $J_{1}$ and $J_{2}$.

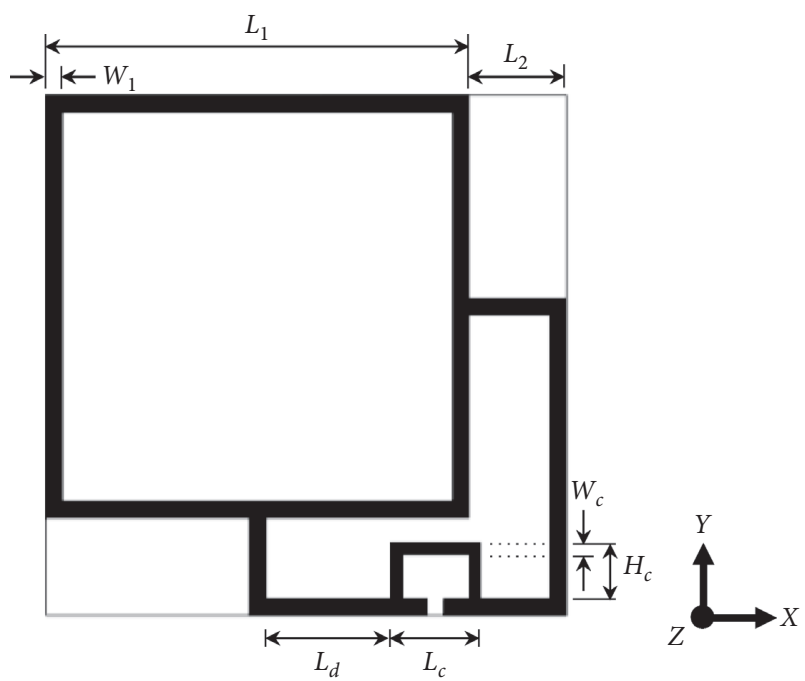

Figure 8: The configuration of UHF-RFID tag antenna.

TABLE 2: Parameters of UHF-RFID tag antenna.

\begin{tabular}{lccccccc}
\hline Parameters & $W_{1}$ & $L_{1}$ & $L_{2}$ & $L_{\mathrm{d}}$ & $W_{\mathrm{c}}$ & $L_{\mathrm{c}}$ & $H_{\mathrm{c}}$ \\
\hline Initial $(\mathrm{mm})$ & 3 & 81.00 & 20.00 & 18.00 & 3 & 15.00 & 12.00 \\
Optimal $(\mathrm{mm})$ & 3 & 77.3 & 17.84 & 24.86 & 2 & 16.38 & 10.26 \\
\hline
\end{tabular}

calculate the impedance $\left(Z_{\mathrm{Tag}}\right)$ and $\left|S_{11}\right|$ of the HF-RFID and UHF-RFID structures in the following equations:

$$
\begin{aligned}
& Z_{\mathrm{Tag}}=\frac{2 Z_{0}\left\{\left[\left(1+S_{11}\right)\left(1+S_{22}\right)\right]-\left(S_{12} S_{21}\right)\right\}}{2 S_{21}+\left[\left(1-S_{11}\right)\left(1+S_{22}\right)\right]+\left(S_{12} S_{21}\right)} \\
& \Gamma=\frac{Z_{\text {chip }}-Z_{\text {tag }}^{*}}{Z_{\text {chip }}+Z_{\text {tag }}}=\frac{\left(R_{\text {chip }}+X_{\text {chip }}\right)-\left(R_{\text {tag }}-X_{\text {tag }}\right)}{\left(R_{\text {chip }}+X_{\text {chip }}\right)+\left(R_{\text {tag }}+X_{\text {tag }}\right)} \\
& \left|S_{11}\right|(\mathrm{dB})=20 \log _{10}(\Gamma) .
\end{aligned}
$$

Figure 14 compares the simulated and measured impedance of HF-RFID and UHF-RFID structures (without IC chips). The simulated impedance of the HF-RFID and UHFRFID structures is $6.08+\mathrm{j} 236.76 \Omega$ at $13.56 \mathrm{MHz}$ and $14.39+\mathrm{j} 147.94 \Omega$ at $922.5 \mathrm{MHz}$. The corresponding measured impedance is $5.81+\mathrm{j} 236.31 \Omega$ and $17.84+\mathrm{j} 147.51 \Omega$. The simulated and measured results are in good agreement.

Figure 15 compares the simulated and measured $\left|S_{11}\right|$ of the UHF-RFID structure. Given $\left|S_{11}\right| \leq-10 \mathrm{~dB}$, the simulation result reveals that the UHF-RFID tag antenna is operable over $894 \mathrm{MHz}-947 \mathrm{MHz}$ ( $53 \mathrm{MHz}$ bandwidth). The measured result shows the operating frequency of $903 \mathrm{MHz}-944 \mathrm{MHz}$ (41 MHz bandwidth). The simulated and measured results are in reasonable agreement.

Since the feature of the proposed tag antenna has the circularly polarized radiation in UHF-RFID band, the properties of circular polarization where the axial ratio (AR) of equal or less than $3 \mathrm{~dB}$ in terms of $\mathrm{AR}$ bandwidth, $\mathrm{AR}$ pattern, and tag antenna gain (in $\mathrm{dBic}$ ) are investigated.

The CP properties of the UHF-RFID tag antenna prototype are measured in an anechoic chamber, as shown in 


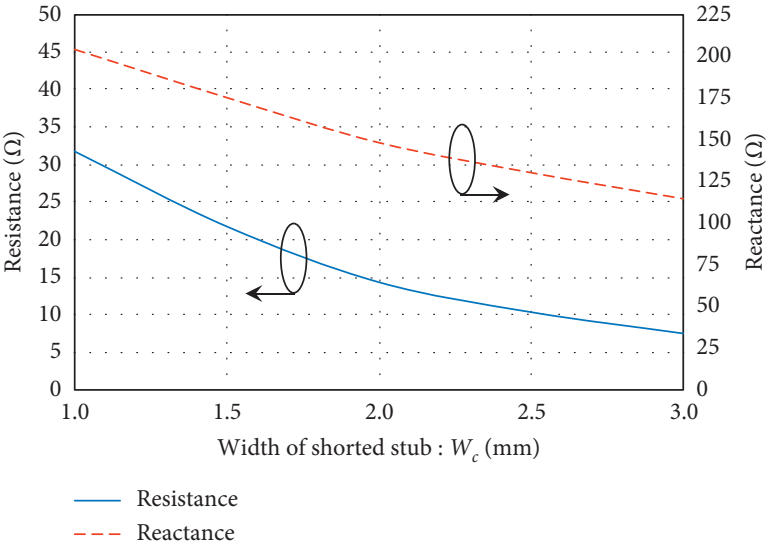

(a)

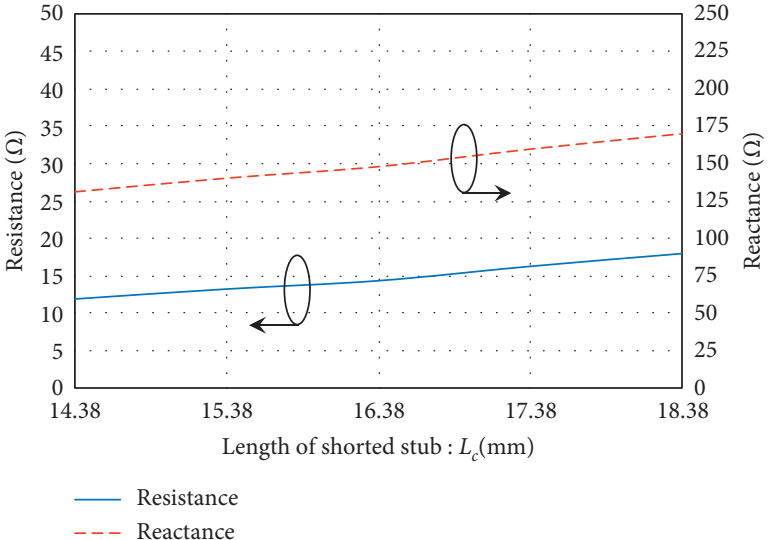

(b)

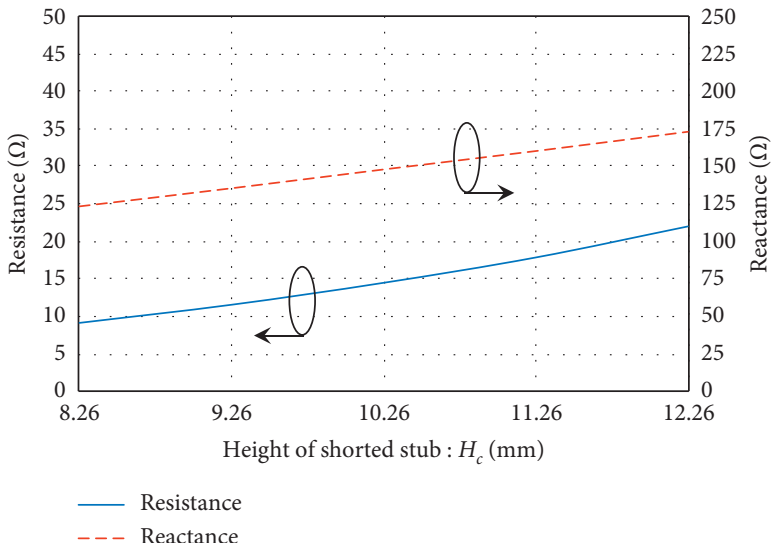

(c)

FigURE 9: The simulated impedance of UHF-RFID tag antenna under varying (a) $W_{\mathrm{c}}$, (b) $L_{\mathrm{c}}$, and (c) $H_{\mathrm{c}}$.

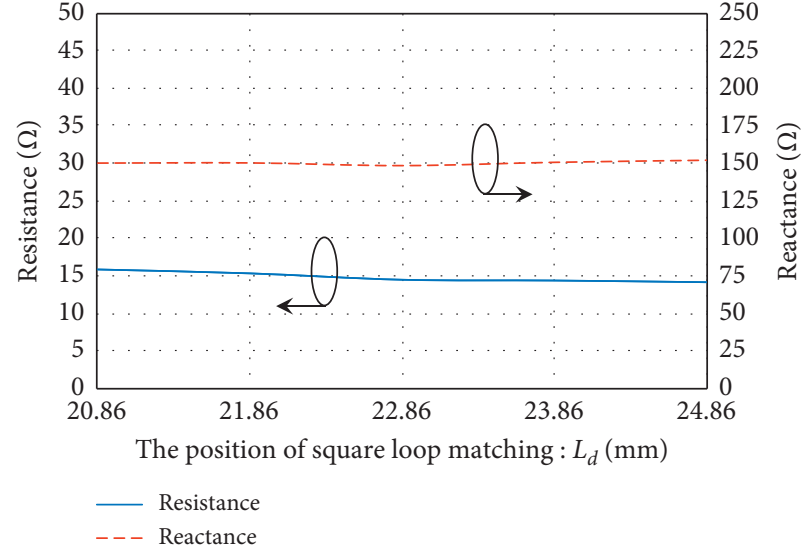

(a)

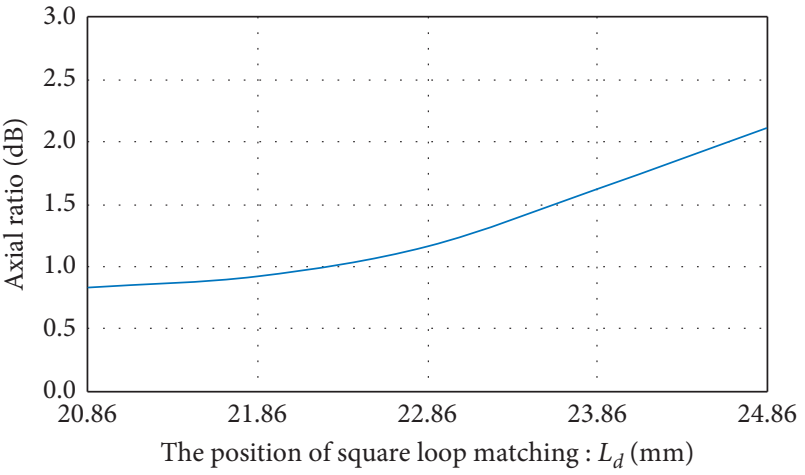

(b)

FIgURE 10: The simulated impedance and axial ratio of UHF-RFID tag antenna under varying $L_{\mathrm{d}}$ : (a) impedance and (b) axial ratio.

Figure 16. Despite the impedance mismatch between the UHF-RFID tag antenna and $50 \Omega$ network analyzer, it has no influence on the radiation characteristics of the tag antenna.

To characterize the AR of the UHF-RFID tag antenna, the standard conical log spiral antennas (ETS-Lindgren) models 3102 (right-hand wound) and 3102L (left-hand wound) are used as the transmitting antennas with lefthanded and right-handed CP radiation. The designed UHFRFID tag antenna under test radiating left-handed CP acted as receiving antenna. The received power was measured from each case of transmitting antenna. The corresponding co-polarized and cross-polarized electric fields are, 


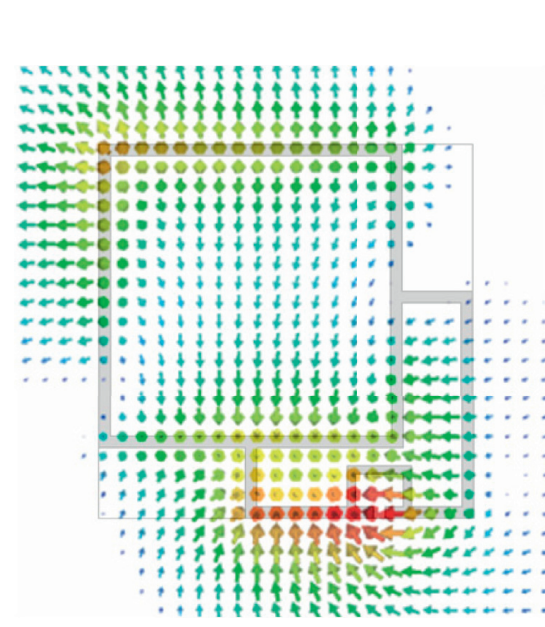

(a)

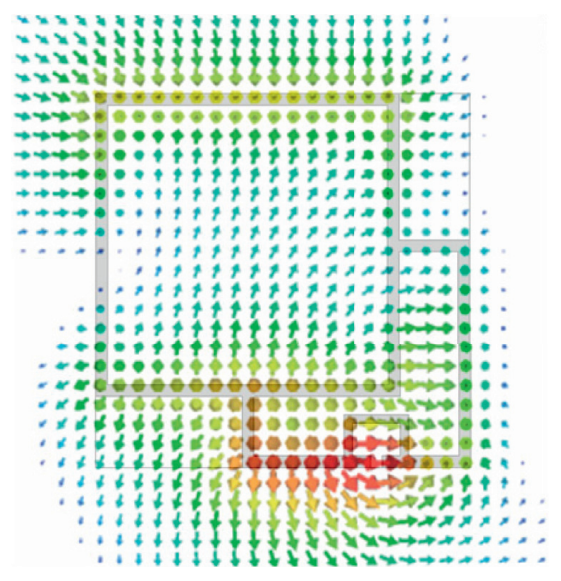

(c)
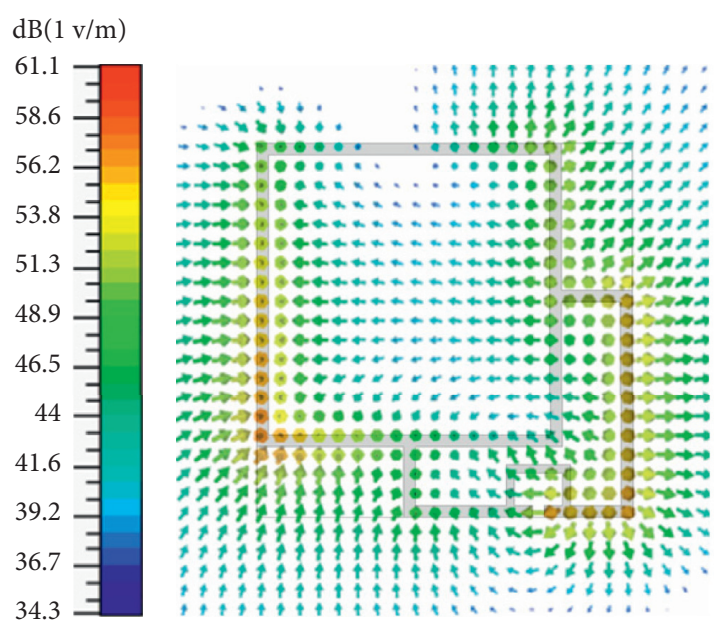

(b)

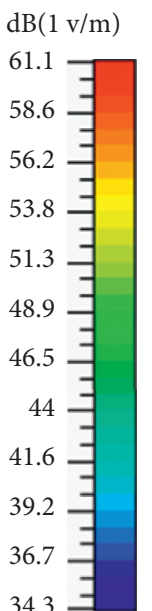

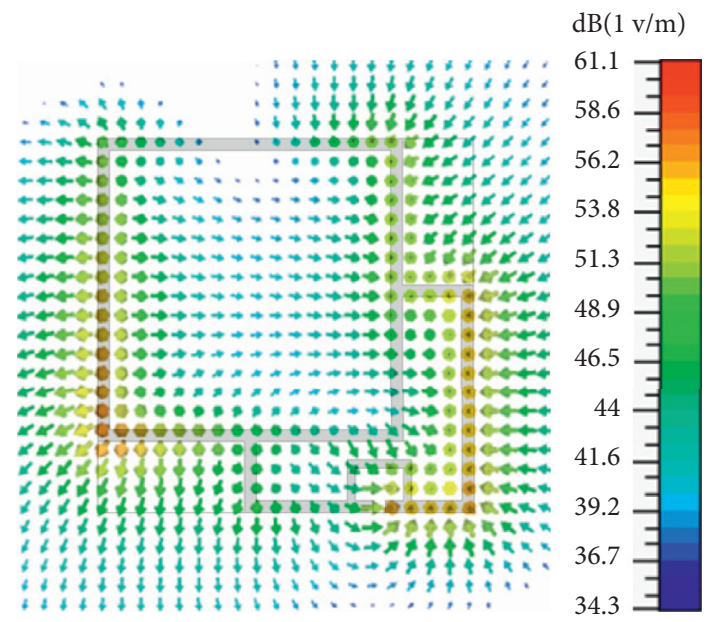

(d)

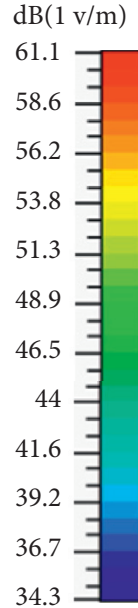

Figure 11: The simulated electric field under variable time periods (T): (a) $t=0$, (b) $t=T / 4$, (c) $t=T / 2$, and (d) $t=3 T / 4$.
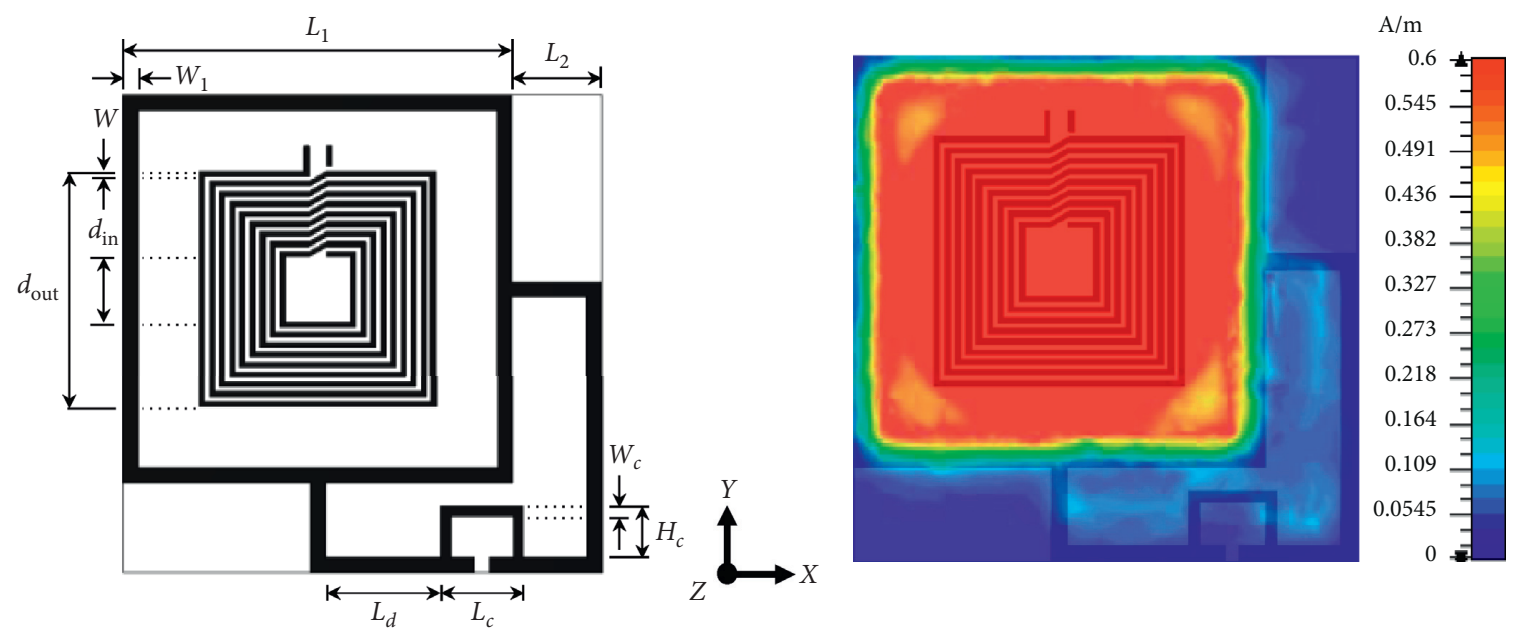

(a)

FIgURE 12: Continued. 


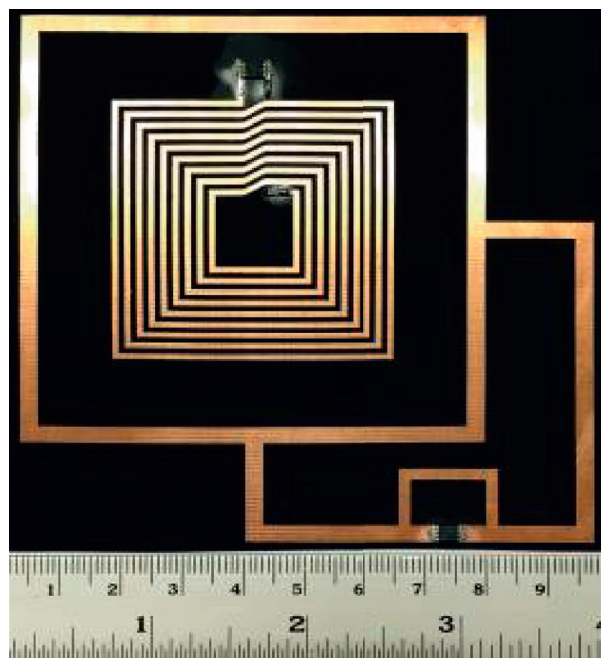

(c)

FiguRE 12: The integrated HF-RFID and UHF-RFID tag antenna: (a) configuration, (b) magnetic field distribution in HF band, and (c) prototype antenna.

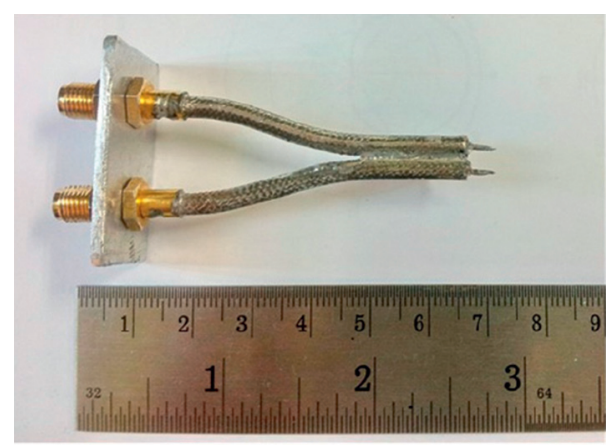

FIGURE 13: A photograph of differential probe.

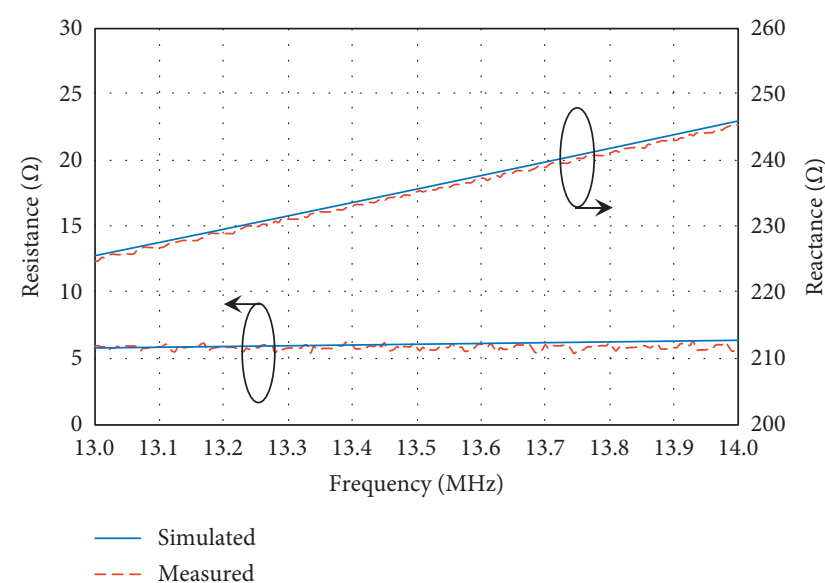

(a)

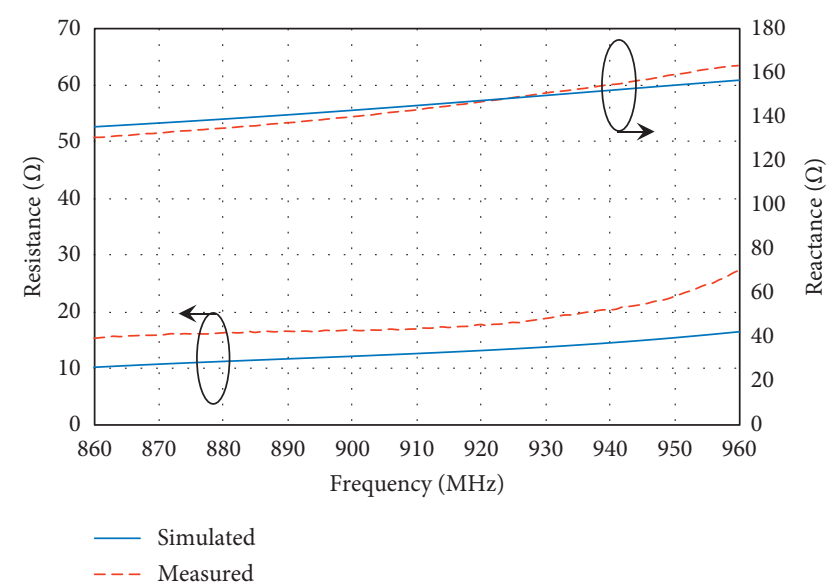

(b)

FIgURE 14: The simulated and measured impedance: (a) HF-RFID structure and (b) UHF-RFID structure.

respectively, obtained in case that the polarizations between the transmitting and receiving antennas are the same sense ( $\left.E_{\text {co-pol }}\right)$ and opposite sense $\left(E_{\mathrm{x}-\mathrm{pol}}\right)$. The AR can be subsequently determined from [36]

$$
\mathrm{AR}(\mathrm{dB})=20 \log \left(\frac{\left|E_{\mathrm{co}-\mathrm{pol}}\right|+\left|E_{\mathrm{x}-\mathrm{pol}}\right|}{\left|E_{\mathrm{co}-\mathrm{pol}}\right|-\left|E_{\mathrm{x}-\mathrm{pol}}\right|}\right) .
$$




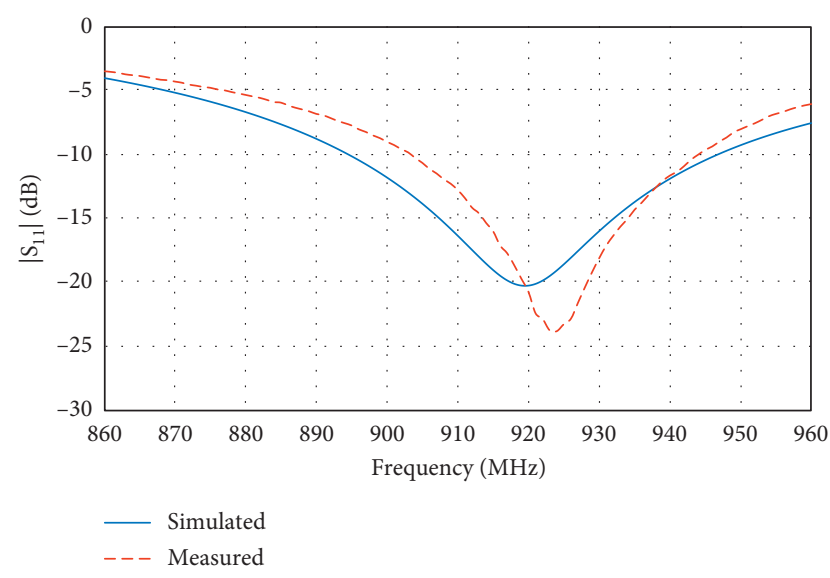

FIgURE 15: The simulated and measured $\left|S_{11}\right|$ of the UHF-RFID tag antenna.

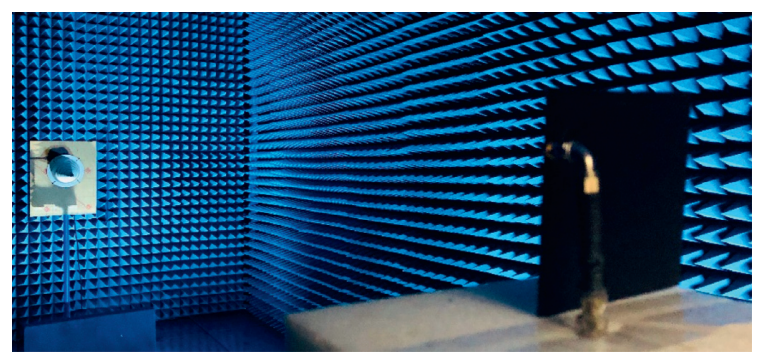

FIgURE 16: The experimental setup for radiation measurement in anechoic chamber.

Figure 17 compares the simulated and measured AR over the RFID frequency from $860 \mathrm{MHz}$ to $960 \mathrm{MHz}$ in boresight direction. The simulated and measured $\mathrm{AR}$ at $922.5 \mathrm{MHz}$ are $1.16 \mathrm{~dB}$ and $1.67 \mathrm{~dB}$, and the simulated and measured axial ratio bandwidths (ARBW) are $63 \mathrm{MHz}(885 \mathrm{MHz}-948 \mathrm{MHz})$ and $75 \mathrm{MHz}(863-938 \mathrm{MHz})$. The simulated and measured results are in reasonable agreement.

In the far-field communication of UHF-RFID system, the radiation pattern including antenna beamwidth is important in practical application. For the proposed tag antenna in UHF-RFID band radiating circular polarization, the so-called AR pattern that superimposes the normalized pattern with the AR as function of angle will be shown. The AR pattern is inscribed by inner and outer envelopes. For specified angle, the ratio of the outer and inner envelopes represents the $\mathrm{AR}$. The ideal $\mathrm{CP}$ is corresponding to zero $\mathrm{dB}$ difference of outer and inner envelopes. In addition, the beamwidth of AR pattern can be considered from angular separation between two points with $-6 \mathrm{~dB}$ of the ideal $\mathrm{CP}$ [37]. Figure 18 compares the simulated and measured $x z$ plane and $y z$-plane of normalized AR patterns at $922.5 \mathrm{MHz}$ of the UHF-RFID tag antenna. The simulated and measured axial ratio beamwidths in boresight direction in $x z$-plane are $104^{\circ}$ and $106^{\circ}$ and those in $y z$-plane are $106^{\circ}$ and $101^{\circ}$.

The realized gain is the significant property of the antenna. For the circularly polarized antenna, the antenna gain is considered from the co-polarized radiation, where the unit of its gain is dBic. The standard circularly polarized antenna model ALR9610BC (Alien Technology) with left-handed CP is used as

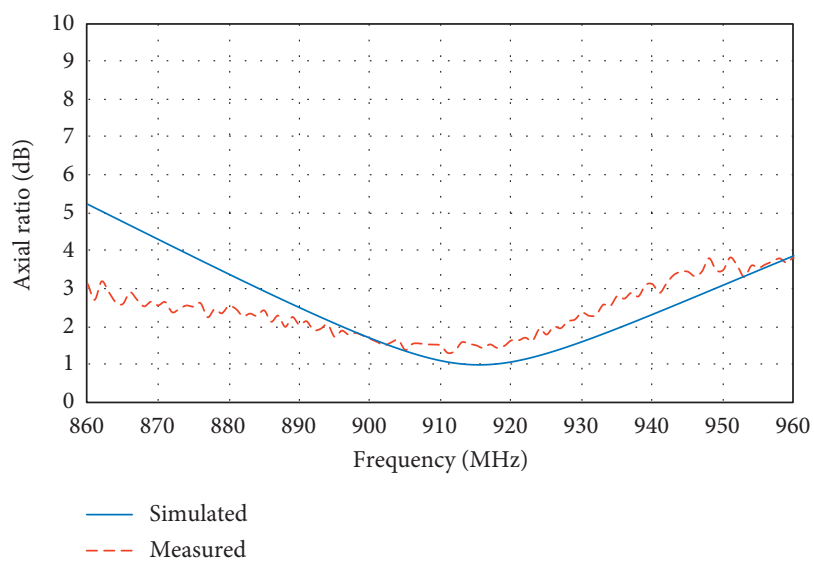

FIgURE 17: The simulated and measured AR of the UHF-RFID tag antenna.

the transmitting antenna. Figure 19 compares the simulated and measured antenna gains over $860 \mathrm{MHz}-960 \mathrm{MHz}$. The simulated and measured maximum gains are $2.45 \mathrm{dBic}$ and $1.08 \mathrm{dBic}$ at $897 \mathrm{MHz}$ and $884 \mathrm{MHz}$, respectively. At the center frequency of $922.5 \mathrm{MHz}$, the simulated and measured antenna gains are $2.08 \mathrm{dBic}$ and $0.31 \mathrm{dBic}$. The large discrepancy could be attributed to impedance mismatch and fabrication loss.

For near-field and far-field communication of HF-RFID and UHF-RFID tag antenna, the reading range must be examined. The reading range of the proposed tag antenna in HFRFID band is mainly influenced from the magnetic field distribution as simulated in Section 2.1. The measurement of magnetic field strength of the proposed tag is difficult. Therefore, the measurement of the reading range will be performed instead. The Arduino Nano and Elechouse NFC module V3 with built-in PCB antenna are used as the reader for the HF-RFID tag antenna. The distance between the reader and the tag antenna is varied, and the maximum reading range is determined. The maximum reading range of the HF-RFID tag antenna is $4.9 \mathrm{~cm}$. This measured reading range coincides with the distance of simulated magnetic field intensity in Figure 3.

For the UHF-RFID tag antenna, the far-field communication based on Friis transmission equation is evaluated. The maximum reading range $\left(R_{\max }\right)$ can be estimated from the effective isotropic radiated power (EIRP) of the UHF-RFID reader and the characteristics of the tag antenna. The calculation of the reading range can be determined from [19].

$$
R_{\max }=\frac{\lambda}{4 \pi} \sqrt{\frac{\mathrm{EIRP} \times G_{\mathrm{tag}} \times\left(1-|\Gamma|^{2}\right) \times \mathrm{PLF}}{P_{\mathrm{tag}}}},
$$

where $\Gamma=10^{\left(\left|S_{11}\right|(\mathrm{dB}) / 20\right)}$.

The characteristics of the tag antenna are the gain of tag antenna $\left(G_{\text {tag }}\right)$, reflection coefficient $(\Gamma)$, polarization loss factor (PLF), and minimum required power for the tag $\left(P_{\text {tag }}\right)$. The maximum reading range of $10.08 \mathrm{~m}$ is calculated under the given EIRP of $3 \mathrm{~W}$, polarization loss factor of unity, and minimum required power for tag of $-15 \mathrm{dBm}$, respectively. In the measurement, the RFID reader model ALR9780 and standard CP reader antenna model ALR9610BC (Alien Technology) are used as the far-field 


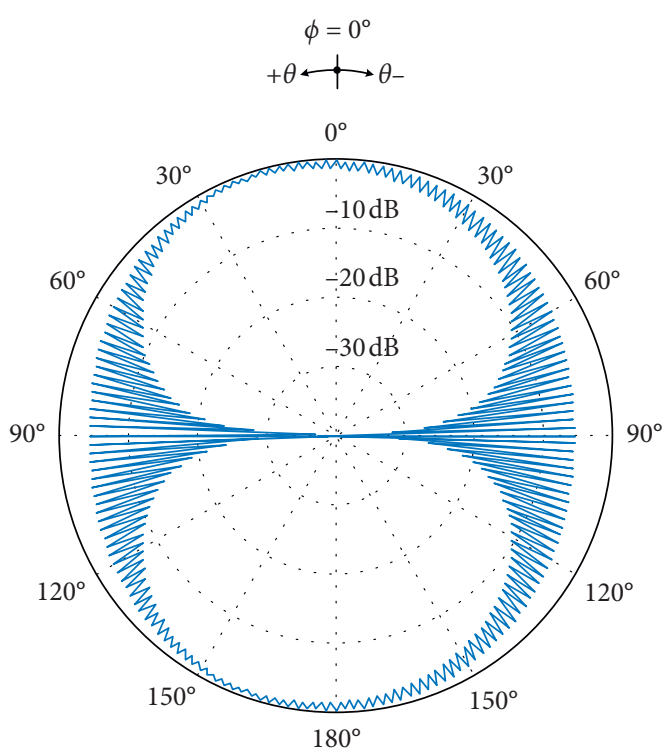

(a)

$\phi=0^{\circ}$

$+\theta \stackrel{\leftrightarrow}{\longrightarrow} \theta$

$0^{\circ}$

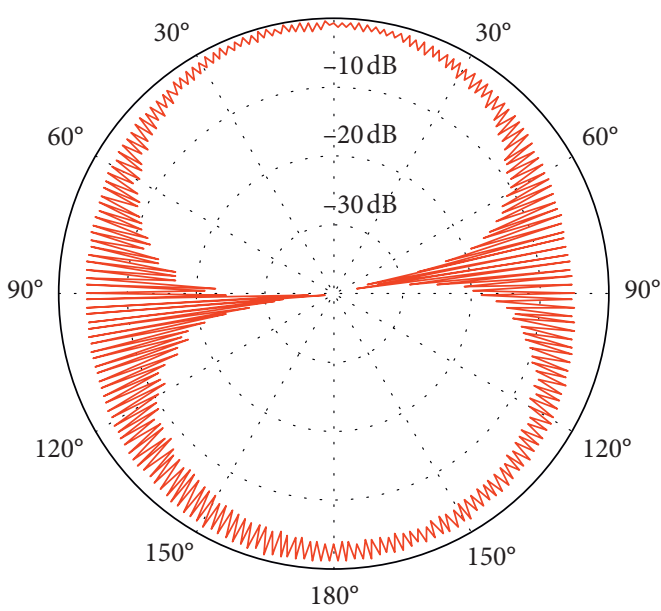

(c)

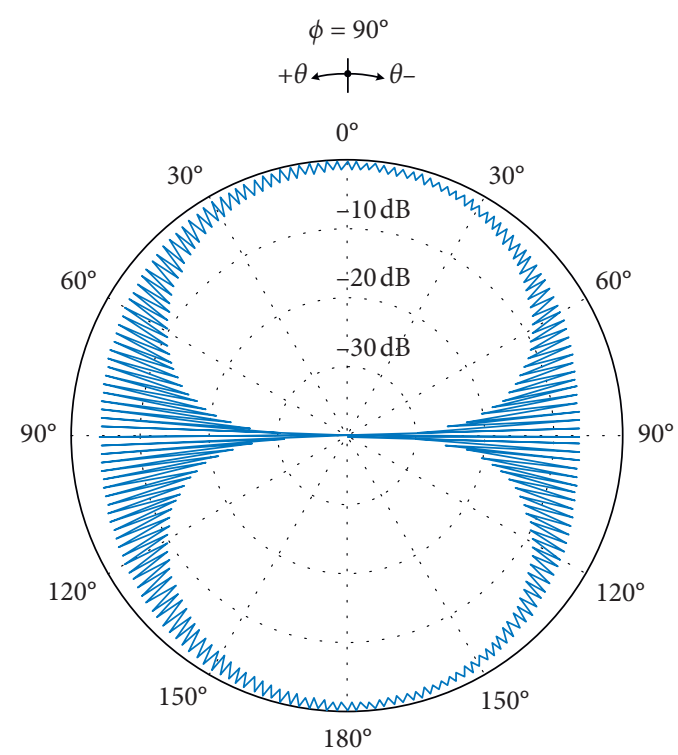

(b)

$\phi=90^{\circ}$

$+\theta \stackrel{\leftrightarrow}{\longleftrightarrow} \theta-$

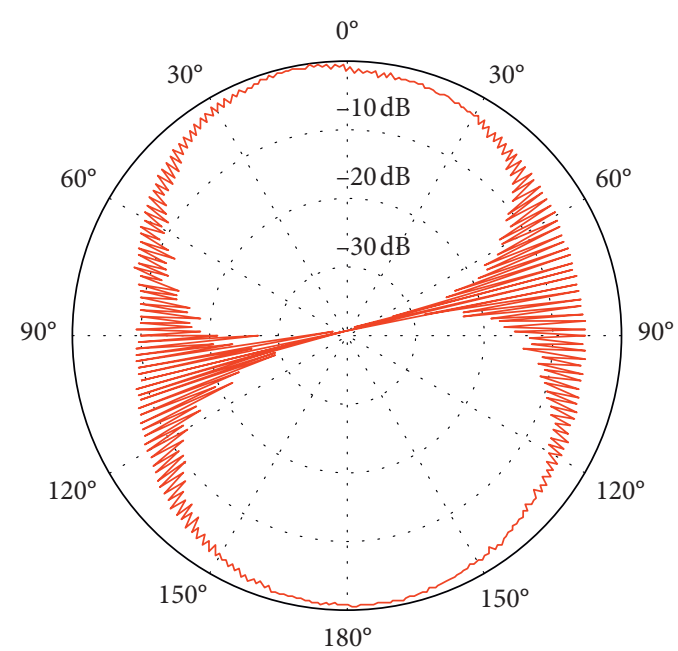

(d)

FIGURE 18: The simulated and measured results of normalized AR pattern of UHF-RFID tag antenna: (a, b) simulated $x z$-plane and $y z$-plane; $(c, d)$ measured $x z$-plane and $y z$-plane.

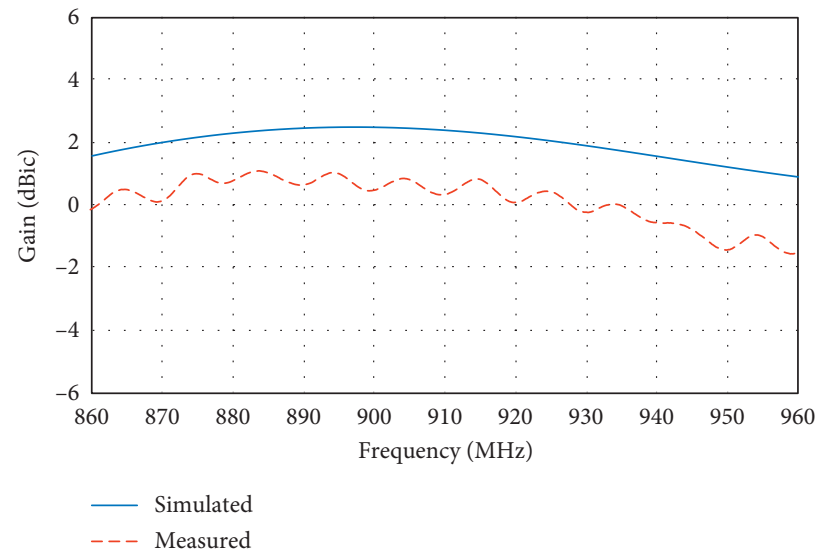

FIgURE 19: The simulated and measured gains of the UHF-RFID tag antenna. 
TABLE 3: Performance comparison of the proposed integrated HF-RFID and UHF-RFID tag antenna with current state of the art in RFID tag antennas.

\begin{tabular}{|c|c|c|c|c|c|}
\hline Reference & Dimension (mm) & $\begin{array}{c}\text { Frequency band } \\
\text { operation }\end{array}$ & $\begin{array}{c}\% \text { fractional bandwidth in UHF } \\
\text { band }\left(\left|S_{11}\right| \leq-10 \mathrm{~dB}\right)\end{array}$ & $\begin{array}{l}\text { Polarization type in } \\
\text { UHF band }\end{array}$ & $\begin{array}{l}\% \text { fractional bandwidth of } \mathrm{CP} \\
\text { in } \mathrm{UHF} \text { band }(\mathrm{AR} \leq 3 \mathrm{~dB})\end{array}$ \\
\hline Proposed & $95 \times 95 \times 0.8$ & $\mathrm{HF} / \mathrm{UHF}$ & 4.44 & Circular pol. & 6.87 \\
\hline$[4]$ & $54 \times 85 \times 0.8$ & $\mathrm{HF} / \mathrm{UHF}$ & 4.01 & Linear pol. & - \\
\hline [5] & $49 \times 83 \times 0.7$ & $\mathrm{HF} / \mathrm{UHF}$ & 0.12 & Linear pol. & - \\
\hline [6] & $54 \times 84 \times 0.8$ & $\mathrm{HF} / \mathrm{UHF}$ & 3.36 & Linear pol. & - \\
\hline [7] & $60 \times 100 \times 0.8$ & $\mathrm{HF} / \mathrm{UHF}$ & 0.58 & Linear pol. & - \\
\hline [8] & $40 \times 40 \times 3.14$ & UHF & 3.45 & Circular pol. & 1.08 \\
\hline [9] & $74 \times 74 \times 1.6$ & UHF & 25.98 & Circular pol. & 0.65 \\
\hline [10] & $100 \times 100 \times 1.6$ & UHF & 1.85 & Circular pol. & 0.86 \\
\hline [11] & $60 \times 60 \times 1.6$ & UHF & 3.55 & Circular pol. & 0.97 \\
\hline$[12]$ & $80 \times 80 \times 1.6$ & UHF & 1.53 & Circular pol. & 1.76 \\
\hline [13] & $85 \times 85 \times 0.4$ & UHF & 3.61 & Circular pol. & 3.50 \\
\hline$[14]$ & $58.6 \times 58.6 \times 0.4$ & UHF & 2.91 & Circular pol. & 0.86 \\
\hline [15] & $35.6 \times 35.6 \times 0.508$ & UHF & 4.06 & Circular pol. & 1.25 \\
\hline [16] & $75 \times 75 \times 0.565$ & UHF & 12.53 & Circular pol. & 2.92 \\
\hline [17] & $56 \times 56 \times 0.4$ & UHF & 14.41 & Circular pol. & 1.64 \\
\hline [18] & $90 \times 90 \times 0.15$ & UHF & 5.65 & Circular pol. & 5.45 \\
\hline [19] & $127 \times 127 \times 0.15$ & UHF & 7.58 & Circular pol. & 6.01 \\
\hline [20] & $54 \times 54 \times 0.2$ & UHF & 10.99 & Circular pol. & 3.91 \\
\hline
\end{tabular}

reader. The measured maximum reading distance of the UHF-RFID tag antenna is $8.7 \mathrm{~m}$. The measured maximum reading range is slightly lower than the calculated result because the measured gain is lower than the simulated one.

A comprehensive comparison of the proposed integrated HF-RFID and UHF-RFID tag antenna with some current state of the art in RFID tag antennas is tabulated in Table 3. The dimension and performance, i.e., single/dual operation band, polarization type of UHF band, and fractional bandwidths $\left(\left|S_{11}\right| \leq-10 \mathrm{~dB}\right.$ and $\left.\mathrm{AR} \leq 3 \mathrm{~dB}\right)$, are compared under the fair-basis condition. The sizes of these antennas are approximately the quarter wavelength of their lowest operating frequencies.

From Table 3, the previously published papers of integrated dual-band HF-RFID and UHF-RFID tag antennas [4-7] were presented with linear polarization in UHF band. These antennas suffer from the polarization loss from misalignment with reader antenna and multipath propagation environment. In [8-20], the presented circularly polarized tag antennas were operated in single band of UHFRFID band. These antennas have immunity from the polarization loss, but they are not suitable for the applications with the lossy material and some dielectric objects due to the natural limitations of UHF band. Apparently, the proposed antenna achieves the wide ARBW of $6.87 \%$, which is relatively large for the compact antenna size.

\section{Conclusion}

The integrated HF-RFID and UHF-RFID tag antenna has been proposed for lossy dielectric and other materials in near-field communication and mitigates polarization loss in far-field communication. The HF-RFID tag antenna of square spiral structure with measured impedance of $5.81+\mathrm{j} 236.31 \Omega$ is conjugate-matched with NT3H2111 chip at $13.56 \mathrm{MHz}$, resulting in the maximum reading range of
$4.9 \mathrm{~cm}$. The circularly polarized UHF-RFID tag antenna using a square loop radiator with cascading square loop feeding structure and shorted stub is realized by the CMA principle to achieve the measured impedance of $17.84+j 147.51 \Omega$ at $922.5 \mathrm{MHz}$. With the enhanced techniques, the measured $\mathrm{AR}$ bandwidth is $75 \mathrm{MHz}$ (863-938 MHz) which widely covers regulated frequency bands in various countries. The gain of the UHF-RFID tag antenna at $922.5 \mathrm{MHz}$ is $0.31 \mathrm{dBic}$, with the maximum reading range of $8.7 \mathrm{~m}$. Essentially, the proposed integrated dual-band HF-RFID and UHF-RFID passive tag antenna is suitable for near-field and far-field communication such as in highway tracking and toll collection applications.

\section{Data Availability}

The data used to support the findings of this study are available from the corresponding author upon request.

\section{Conflicts of Interest}

The authors declare that there are no conflicts of interest regarding the publication of this paper.

\section{Acknowledgments}

The authors would like to express their deep appreciation to Prof. Takeshi Fukusako, Kumamoto University, Japan, for valuable suggestions on CMA for circularly polarized antenna design.

\section{References}

[1] K. Finkenzeller, RFID Handbook: Fundamentals and Applications in Contactless Smart Cards and Identification, John Wiley and Sons, Hoboken, NJ, USA, 2003. 
[2] M. Bolic, D. Simplot-Ryl, and I. Stojmenovic, RFID Systems Research Trends and Challenges, John Wiley and Sons, Hoboken, NJ, USA, 2010.

[3] M. A. Kenari, M. N. Moghadasi, R. A. Sadeghzadeh, B. S. Virdee, and E. Limiti, "Dual-band RFID tag antenna based on the hilbert-curve fractal for HF and UHF applications," IET Circuits, Devices and Systems, vol. 10, no. 2, pp. 140-146, 2016.

[4] T. Deleruyelle, P. Pannier, M. Egels, and E. Bergeret, "Dual band mono-chip HF-UHF tag antenna," in Proceedings of the 2010 IEEE Antennas and Propagation Society International Symposium, pp. 1-4, Toronto, Canada, July 2010.

[5] F. Paredes, I. Cairó, S. Zuffanelli, G. Zamora, J. Bonache, and F. Martin, "Compact design of UHF RFID and NFC antennas for mobile phones," IET Microwaves, Antennas \& Propagation, vol. 11, no. 7, pp. 1016-1019, 2017.

[6] Z. L. Ma, L. J. Jiang, J. Xi, and T. T. Ye, "A single-layer compact HF-UHF dual-band RFID tag antenna," IEEE Antennas and Wireless Propagation Letters, vol. 11, pp. 12571260, 2012.

[7] P. Iliev, P. Le Thuc, C. Luxey, and R. Staraj, "Dual-band HFUHF RFID tag antenna," Electronics Letters, vol. 45, no. 9, pp. 439-441, 2009.

[8] J.-H. Lu and B.-S. Chang, "Planar circularly polarized tag antenna with compact operation for UHF RFID application," Journal of Electromagnetic Waves and Applications, vol. 27, no. 15, pp. 1882-1891, 2013.

[9] R. Liu, Y. Yao, Y. Zhang et al., "Design of a novel circularly polarized annular-ring RFID tag antenna for metallic surfaces," in Proceedings of the 2013 Asia-Pacific Microwave Conference Proceedings (APMC), Seoul, South Korea, November 2013.

[10] C.-H. Yeh, P.-S. Ho, C.-W. Lin, and C.-Y.-D. Sim, "Circularly polarized UHF RFID tag antenna with capacitive loading technique," in Proceedings of the 2016 IEEE 5th Asia-Pacific Conference on Antennas and Propagation (APCAP), Kaohsiung, Taiwan, July 2016.

[11] W.-C. Chen, H.-M. Chen, and Y.-F. Lin, "Capacitive coupling-feed circularly polarized RFID tag antenna mounted on metallic plane," in Proceedings of the 2016 IEEE 5th AsiaPacific Conference on Antennas and Propagation (APCAP), Kaohsiung, Taiwan, July 2016.

[12] X. Qian, G.-Q. Zhang, X. Lei, L. Hou, and S.-H. Ma, "Design of a broadband circularly polarized UHF RFID tag antenna for metallic objects," in Proceedings of the 2015 Asia-Pacific Microwave Conference (APMC), Nanjing, China, December 2015.

[13] H.-D. Chen, R.-B. Tsai, C.-H. Tsai, and T.-Y. Liu, "Inverted-Z RFID tag antenna for circularly polarized operation," in Proceedings of the 2014 International Symposium on Antennas and Propagation Conference, Kaohsiung, Taiwan, December 2014.

[14] H.-D. Chen, C.-Y.-D. Sim, C.-H. Tsai, and C. Kuo, "Compact circularly polarized meandered-loop antenna for UHF-band RFID tag," IEEE Antennas and Wireless Propagation Letters, vol. 15, pp. 1602-1605, 2016.

[15] H. H. Tran, S. X. Ta, and I. Park, "A compact circularly polarized crossed-dipole antenna for an RFID tag," IEEE Antennas and Wireless Propagation Letters, vol. 14, pp. 674$677,2015$.

[16] X. Gao and Z. Shen, "UHF/UWB tag antenna of circular polarization," IEEE Transactions on Antennas and Propagation, vol. 64, no. 9, pp. 3794-3802, 2016.
[17] D. Inserra and G. Wen, "Compact crossed dipole antenna with meandered series power divider for UHF RFID tag and handheld reader devices," IEEE Transactions on Antennas and Propagation, vol. 67, no. 6, pp. 4195-4199, 2019.

[18] H.-D. Chen, C.-H. Tsai, C.-Y.-D. Sim, and C.-Y. Kuo, "Circularly polarized loop tag antenna for long reading range RFID applications," IEEE Antennas and Wireless Propagation Letters, vol. 12, pp. 1460-1463, 2013.

[19] C.-H. Tsai, H.-D. Chen, and C.-Y.-D. Sim, "High-gain circularly-polarized loop tag antenna for long reading distance RFID application," Microwave and Optical Technology Letters, vol. 56, no. 10, pp. 2335-2341, 2014.

[20] J.-H. Lu and B.-S. Chang, "Planar compact square-ring tag antenna with circular polarization for UHF RFID applications," IEEE Transactions on Antennas and Propagation, vol. 65 , no. 2 , pp. 432-441, 2017.

[21] R. Garbacz and R. Turpin, "A generalized expansion for radiated and scattered fields," IEEE Transactions on Antennas and Propagation, vol. 19, no. 3, pp. 348-358, 1971.

[22] R. Harrington and J. Mautz, "Theory of characteristic modes for conducting bodies," IEEE Transactions on Antennas and Propagation, vol. 19, no. 5, pp. 622-628, 1971.

[23] R. Harrington and J. Mautz, "Computation of characteristic modes for conducting bodies," IEEE Transactions on Antennas and Propagation, vol. 19, no. 5, pp. 629-639, 1971.

[24] M. Khan and D. Chatterjee, "Characteristic mode analysis of a class of empirical design techniques for probe-fed, U-slot microstrip patch antennas," IEEE Transactions on Antennas and Propagation, vol. 64, no. 7, pp. 2758-2770, 2016.

[25] E. Antonino-Daviu, M. Cabedo-Fabres, M. Sonkki, N. Mohamed Mohamed-Hicho, and M. Ferrando-Bataller, "Design guidelines for the excitation of characteristic modes in slotted planar structures," IEEE Transactions on Antennas and Propagation, vol. 64, no. 12, pp. 5020-5029, 2016.

[26] Z. Liang, J. Ouyang, F. Yang, and L. Zhou, "Design of license plate RFID tag antenna using characteristic mode pattern synthesis," IEEE Transactions on Antennas and Propagation, vol. 65, no. 10, pp. 4964-4970, 2017.

[27] F. H. Lin and Z. N. Chen, "Low-profile wideband metasurface antennas using characteristic mode analysis," IEEE Transactions on Antennas and Propagation, vol. 65, no. 4, pp. 17061713, 2017.

[28] Y. Luo, Z. N. Chen, and K. Ma, "Enhanced bandwidth and directivity of a dual-mode compressed high-order mode stubloaded dipole using characteristic mode analysis," IEEE Transactions on Antennas and Propagation, vol. 67, no. 3, pp. 1922-1925, 2019.

[29] H. A. Wheeler, "Simple inductance formulas for radio coils," Proceedings of the IRE, vol. 16, no. 10, pp. 1398-1400, 1928.

[30] S. S. Mohan, M. del Mar Hershenson, S. P. Boyd, and T. H. Lee, "Simple accurate expressions for planar spiral inductances," IEEE Journal of Solid-State Circuits, vol. 34, no. 10, pp. 1419-1424, 1999.

[31] CST Studio Suite (User's Manual), 2019.

[32] B. Luadang, A. Sakonkanapong, S. Dentri, R. Pansomboon, and C. Phongcharoenpanich, "NFC-enabled far-field antenna on PET flexible substrate for 3G/4G/LTE mobile devices," IEEE Access, vol. 7, pp. 171966-171973, 2019.

[33] L. W. Mayer and A. L. Scholtz, "A dual-band HF/UHF antenna for RFID tags," in Proceedings of the 2008 IEEE 68th Vehicular Technology Conference, pp. 1-5, Calgary, Canada, September 2008. 
[34] Y. Chen and C. F. Wang, Characteristic Modes: Theory and Applications in Antenna Engineering, John Wiley and Sons, Hoboken, NJ, USA, 2015.

[35] X. Qing, C. K. Goh, and X. Chen, "Impedance characterization of RFID tag antennas and application in tag co-design," IEEE Transactions on Microwave Theory and Techniques, vol. 57, no. 5, pp. 1268-1274, 2009.

[36] P. Kildal, "Characterization of Antennas," in Foundations of Antennas: A Unified Approach, pp. 21-90, Studentlitteratur, Lund, Sweden, 2000.

[37] C. A. Balanis, "Polarization Measurements," in Antenna Theory: Analysis and Design, pp. 1038-1043, John Wiley and Sons, Hoboken, NJ, USA, 2005. 